\title{
Cell Death During Gangliogenesis in the Leech: Bipolar Cells Appear and Then Degenerate in All Ganglia
}

\author{
R. R. Stewart, ${ }^{1, a}$ W.-Q. Gao, ${ }^{1}$ A. Peinado, ${ }^{1}$ B. Zipser, ${ }^{2}$ and E. R. Macagno' \\ 'Department of Biological Sciences, Columbia University, New York, New York 10027; and 'Department of Physiology, \\ Michigan State University, East Lansing, Michigan 48824
}

The bipolar cells can be recognized very early during gangliogenesis in the leech central nervous system by their expression of antigens that are recognized by the monoclonal antibody Laz1-1. They are the first cells to express these antigens, which are later shared with a distinct set of other cells in the leech nervous system. Their processes extend several segments rostrally and caudally along the forming interganglionic connective nerves; they are first found in anterior segments and gradually appear in more posterior ones over the course of 2-3 d. At about the time bipolar cells appear in the neuromeres of the tail ganglion, those in the most anterior segmental ganglia begin to degenerate. Degeneration proceeds caudally over the next $3 \mathrm{~d}$, until all bipolar cells have disappeared. Bipolar cells are, thus, members of that class of cells that exists for only a short period in neurogenesis and then presumably disappears once its functions are no longer required. These cells' morphology and appearance at the earliest stages in the formation of the interganglionic connective nerves are suggestive of a role in the establishment of these longitudinal pathways in the leech CNS.

A characteristic feature of neurogenesis in vertebrates, as well as in many invertebrates, is the overproduction of cells and a subsequent decrease in their number. This decrease is due largely, if not exclusively, to naturally-occurring cell death, a phenomenon that has been the subject of numerous investigations, particularly in the past several decades (for recent reviews, see Truman, 1984, and Purves and Lichtman, 1985). In general, cell death in vertebrates does not appear to be cell-specific, but seems rather to occur randomly in a population of functionally equivalent neurons as a result of competitive interactions designed to match the size of the population to the requirements of their targets (Hamburger and Oppenheim, 1982). However, there are some cases in which specific neurons die (e.g., the Rohon-Beard cells of the spinal cord; Lamborghini, 1981; Spitzer and Lamborghini, 1981). Among invertcbrates, with their much smaller numbers of neurons, the death of specific cells is

\footnotetext{
Received Oct. 2, 1986; revised Dec. 3, 1986; accepted Dec. 19, 1986.

We thank Nicholas Necles for help with the photography. This work was supported in part by NIH Grant NS-20336.

Correspondence should be addressed to E. R. Macagno, 1003B Fairchild, Columbia University, New York, NY 10027.

a Present address: Department of Pharmacology, Biocenter, Basel 4056, Switzcrland.

Copyright $(1987$ Society for Neuroscience $0270-6474 / 87 / 061919-09 \$ 02.00 / 0$
}

a well-documented phenomenon [e.g., in the nematode $\mathrm{Cae}$ norhabditis elegans (Horvitz et al., 1982) and in the grasshopper (Bate et al., 1981)], but instances that probably lack cell specificity have also been reported. For example, in the visual systems of arthropods [e.g., of the crustacean Daphnia magna (Macagno, 1979) and of the insects Danaus plexippus plexippus (Nordlander and Fdwards, 1968, 1969) and Schistocerca gregaria (Anderson, 1978)], cell death appears to be nonspecific and to adjust the size of interneuron populations to the size of the photoreceptor field. The death of specific cells can serve 2 additional functions. One is the removal of cells that have only a temporary role during development and are thereafter superfluous, a function that is suggested by observations in several species (Truman, 1984). The other is to delete unnecessary cells that arise because of obligate patterns of cell division that produce other, required cells, as has been reported in $C$. elegans (Sulston and Horvitz, 1977).

Overproduction of cells, followed by a decline in their number, has recently been documented as well in the segmental ganglia of the hirudinid leeches Haemopis marmorata (Stewart et al., 1986) and Hirudo medicinalis (C. Baptista, W.-Q. Gao and $\mathrm{E}$. Macagno, unpublished observation). Leeches have 21 segmental ganglia; in adults of these 2 species, most contain about 400 neurons. The main exceptions are the "sex" ganglia, those found in the 5th and 6th body segments along with the sexual organs; these ganglia contain several hundred additional neurons (Macagno, 1980). In both species and in the ganglia of all segments studied, the number of cells found at $10 \mathrm{~d}$ (about one-third of embryogenesis at $24^{\circ} \mathrm{C}$ ) exceeds the number found $10 \mathrm{~d}$ later. This decrease results, at least in part, from cell degeneration, since pycnotic figures were seen in the serial sections used to determine the number of cells in each ganglion. In addition to the segmental ganglia, leeches have much larger head and tail ganglia, but changes in cell number during development have not yet been studied in either.

In this report we present evidence for the death of specific cclls in the ventral nerve cord of hirudinid leeches during the middle third of embryogenesis. We describe here the death of a type of cell we have identified in the CNS of Hirudo medicinalis using the monoclonal antibody (MAb) Laz1-1. These cells are bipolar in shape (and are thus named "bipolar cells") and are found in pairs in all embryonic neuromeres. They extend processes both anteriorly and posteriorly at a stage when longitudinal tracts are first beginning to form, remain in this differentiated state for several days, and then all die.

A preliminary report of this work has been published (Stewart and Macagno, 1985). 


\section{Materials and Methods}

Hirudo medicinalis embryos were obtained as described previously (Fernandez and Stent, 1982). Gravid leeches were placed in plastic boxes filled with moist sphagnum moss and maintained in an incubator at $24 \pm 1^{\circ} \mathrm{C}$. Boxes were checked every other day for cocoons, which contain between 10 and 20 embryos. Once found, the cocoons were kept for 7-10 d, after which the embryos were removed and maintained until used in stcrile dilutc Instant Ocean (Ward's Scientific; $0.5 \mathrm{gm} / \mathrm{litcr}$ in distilled water). Staging was done according to time after egg deposition and by means of standard criteria (see Fernandez and Stent, 1982).

Marking bipolar cells with Lucifer yellow. Embryonic cells were injected with the fluorescent dye Lucifer yellow (LY) using a compound microscope equipped with Nomarski optics, a $40 \times$ water-immersion lens and a $50 \mathrm{~W}$ mercury light source for visualizing injected cells. Dyefilled microelectrodes were positioned by means of a hydraulically driven micromanipulator (Narashige) mounted on the microscope stage. Microelectrodes were made from thin-wall capillary glass (No. 30-300 ; Frederick-Haer Co.) and had resistances of 80-100 M $($ as measured in $0.1 \mathrm{M} \mathrm{LiCl}$ ). Prior to being filled, they were bent near the tip using a heated nichrome wire to facilitate working at a very shallow angle under the water-immersion objective.

Bcfore disscction, an cmbryo was anacsthetized in standard lecch Ringer's solution (Muller et al., 1981) containing 8\% ethanol. The remaining yolk was then removed by pulling apart the muscular membrane surrounding both the yolk and germinal plate at a site opposite to the germinal plate, and the embryo fastened with fine metal pins onto a glass slide covered with a thin layer of Sylgard. A fine pin was used to cut along the dorsal midline and expose the ventral nerve cord. Bipolar cells were identified by their characteristic positions (see Results) and filled with LY by passing hyperpolarizing current pulses through the dye-filled microelectrode after penetrating a cell. We typically used pulses of about $1 \mathrm{nA}$ and $0.5 \mathrm{sec}$ duration at a rate of $1 \mathrm{~Hz}$. The success of the injection was monitored by viewing the preparation directly on the microscope, using epifluorescence. Once the injections were deemed satisfactory, the embryo was fixed on the Sylgard-coated slide or transferred to and repinned in a Sylgard-coated plastic petri dish. The fixation procedure is described in the following section. After fixation, some of the embryos were examined and photographed before antibody labeling by dehydrating them in an ethanol series (70-100\%), clearing them in methyl salicylate, and then mounting them on a slide in methyl salicylate. The embryo could then be retrieved for labeling with the antibody Laz1-1 by immersing the slide in 100\% ethanol, removing the coverslip, and rehydrating the embryo. We found that this procedure did not eliminate Lazl-1 labeling of bipolar cells. Alternatively, the antibody labeling was carried out before examination and photography.

Antibody labeling of embryos. Embryos were processed with the MAb Laz1-1 in order to visualize the bipolar cells. Laz1-1 is a mouse MAb raised against the adult nervous system of the leech Haemopis marmorata. Embryos whose bipolar cells had been marked with Lucifer yellow (LY) were fixed in 4\% paraformaldehyde in $0.1 \mathrm{~m}$ sodium phosphate buffer $(\mathrm{pH} \mathrm{7.4)}$ for $30 \mathrm{~min}$ to $1 \mathrm{hr}$ at room temperature and then processed for labeling with Laz1-1 as described below. Embryos that were processed only for antibody labeling were fixed overnight at $4^{\circ} \mathrm{C}$ in $4 \%$ paraformaldehyde, $0.1 \%$ picric acid in $0.1 \mathrm{~m}$ sodium phosphate buffer ( $\mathrm{pH}$ 7.4). Fixed embryos were rinsed twice daily in PBS (pH 7.4) containing $0.01 \%$ sodium azide for $1-2 \mathrm{~d}$ to remove the fixative. The tissue was then incubated in antibody at a dilution of 1:1 in PBS containing $0.2 \%$ Triton X-100 (Sigma). Embryos were left in antibody overnight at $4^{\circ} \mathrm{C}$, after which they were given two 15 min rinses in PBS before being incubated in a secondary antibody for $1-2 \mathrm{hr}$ at room temperature or overnight at $4^{\circ} \mathrm{C}$. The secondary antibody was a goat anti-mouse IgG (Cappel) conjugated to either rhodamine or fluorescein.

\section{Results}

Initial labeling of bipolar cells with Laz1-1

In leeches, the left and right sides of the germinal plate are derived from 5 bilateral pairs of stem cell bandlets (Fernandez and Stent, 1982; Zackson, 1984; Stent and Weisblat, 1985). These give rise to, among other tissues, 32 metameric neuromeres: The first $4(\mathrm{H} 1-\mathrm{H} 4)$ fuse to form the subesophageal ganglion, the next 21 become the segmental ganglia (SG1-SG21), and the 7 most posterior (T1-T7) fuse to form the tail ganglion.

Each neuromere is first recognizable as a pair of bilateral primordia that is clearly separated by a small gap at the midline. Along the length of the embryo, however, the primordia on each side are closely apposed (see Fig. 1). It is at this early stage of ganglionic differentiation that the bipolar cells begin to express detectable levels of the antigens that are recognized by the MAb Lazl-1 (Fig. 1). Their somata can be seen near the dorsal aspect of each neuromere, close to its posterior margin. When they first label with Lazl-1, bipolar cells are spindle-shaped and extend ipsilateral processes both anteriorly and posteriorly. The processes from cells in adjacent segments overlap, appearing to form a pair of railroad tracks extending along the anteroposterior axis of the embryo (Fig. 1A). In general, the somata of these cells become more rounded as they mature.

Several stages in the differentiation of bipolar cells can be seen in a single embryo, since anterior segments differentiate earlier than those located more posteriorly. A consequence of this is that bipolar cells can be recognized earlier in more anterior regions. In a 7-d-old embryo (Fig. $1 A$ ), bipolar cells labeled with Laz1-1 can be seen in the anterior 13 metameric ganglia, $\mathrm{H1}-$ $\mathrm{H} 4$ and SGl-SG9. By $7.5 \mathrm{~d}$ (Fig. 2), bipolar cells are labeling as posteriorly as SG15 (see Fig. $2 B$ ). At this time, in more antcrior segments, the ganglionic primordia have coalcsced and several other ganglionic cells have also begun to express the Laz1-1 antigens. By now, some of the bipolar cells have undergone their typical change in cell body. While the immature posterior bipolar cells still have an elongated cell body shape (Fig. $2 B$ ), the more mature cells in the anterior ganglia have become more rounded (Fig. 2A). At $8 \mathrm{~d}$ (Fig. 3), labeled bipolar cells can be seen as far caudally as SG19 and, by $10 \mathrm{~d}$, as far as T7. Again, in more mature anterior ganglia (Fig. $3 \mathrm{C}$ ), the bipolar cells are round and are surrounded by an increasing number of other ganglionic cells expressing Laz1-1 antigens, while caudally, in segments with as-yet-unfused ganglionic primordia (Fig. $3 D$ ), fusiform bipolar cells are still the only cells expressing the Laz1-1 antigens. We found some variability (about $\pm 6 \mathrm{hr}$ ) in the exact age when bipolar cells in any particular segment first labeled with Laz1-1, even among animals from the same clutch.

\section{Double-labeling of bipolar cells}

In order to examine the full morphology of bipolar cells and to see whether they stained throughout with Laz1-1, we injected cells with LY. Bipolar cells were identified by their characteristic positions in live embryos viewed with Nomarski optics, and were injected with the dye as described under Materials and Methods. Staining with Laz1-1 served to confirm the identification. A total of 13 apparently healthy bipolar cells, along with 6 that were clearly dying (see below), were injected with dye in several segments of 7-10 embryos. Examination of the healthy cells revealed the presence of only ipsilateral projections, extending through several segments along the nerve cord (Fig. 4A). The anterior projection is generally the longer one, reaching from 3 to 5 ganglia rostrally, while the posterior projection is the shorter, reaching from 2 to 3 ganglia caudally. Numerous short, thin branches extend laterally into the neuropils of these ganglia from the large longitudinal processes (Fig. 4A). Comparison of the patterns of staining of the same cell by Lucifer yellow and by Lazl-1 suggests that the antigens recognized by the antibody are expressed throughout the cell. The dye-filled bipolar cells that were clearly degenerating will be discussed next. 

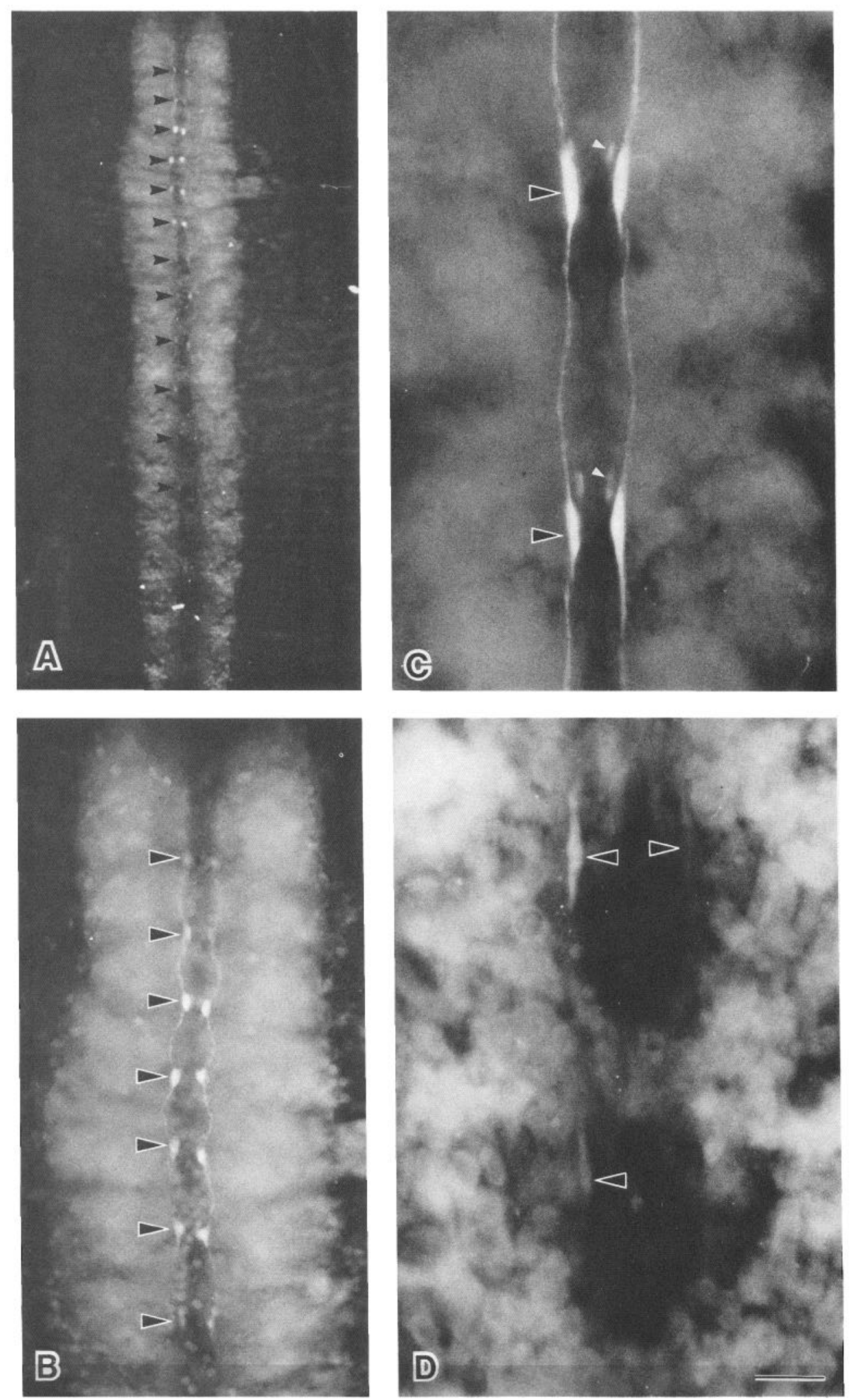

Figure 1. Labeling of bipolar cells with Laz1-1 at $7 \mathrm{~d}$ of age. $A$, Low-power photomicrograph of the germinal plate. The paired bipolar cells are indicated by small, black arrowheads. In this preparation, bipolar cells labeled in the first 4 metameric ganglia of the head region (H1-H4) and in the first 9 segmental ganglia of the body (SG1-SG9). H1-H4 fuse later in development to form the subesophageal ganglion. The tissue on either side of the germinal plate is the larval muscular integument that surrounds the yolk. This temporary integument is resorbed as the lateral edges of the germinal plate expand and encompass the yolk. The larval mouth is not shown, but is anterior to H1. B, High-magnification photomicrograph of the anterior end of the germinal plate. The paired bipolar cells of the first 7 ganglia (H1-H4 and SG1-SG3) are indicated by arrowheads. The bipolar cells appear to be linked from ganglion to ganglion by their processes. $C$, Bipolar cells of SG1 and SG2 from a 7 d embryo that is different from the one shown in $A$ and $B$. The left bipolar cell in each SG is indicated by the black arrowhead. The small, white arrowhead points to the right cell of a pair medial to the bipolar cells. This is the second pair of cells to label with the MAb Laz1-1 in each ganglion. $D$, Bipolar cells of SG11 and SG12 from the same embryo as in $C$ are indicated by arrowheads. In SG12, the right bipolar cell is not labeled. There is a large space or gap between the 2 bipolar cells in SG11, which is not seen later in development; this gap is filled in as development proceeds, as can be seen by viewing the embryo in $A$ from posterior towards anterior. Anterior is towards the top. Scale bar in $D: 130 \mu \mathrm{m}$ for $A, 50 \mu \mathrm{m}$ for $B$, and $20 \mu \mathrm{m}$ for $C$ and $D$. 

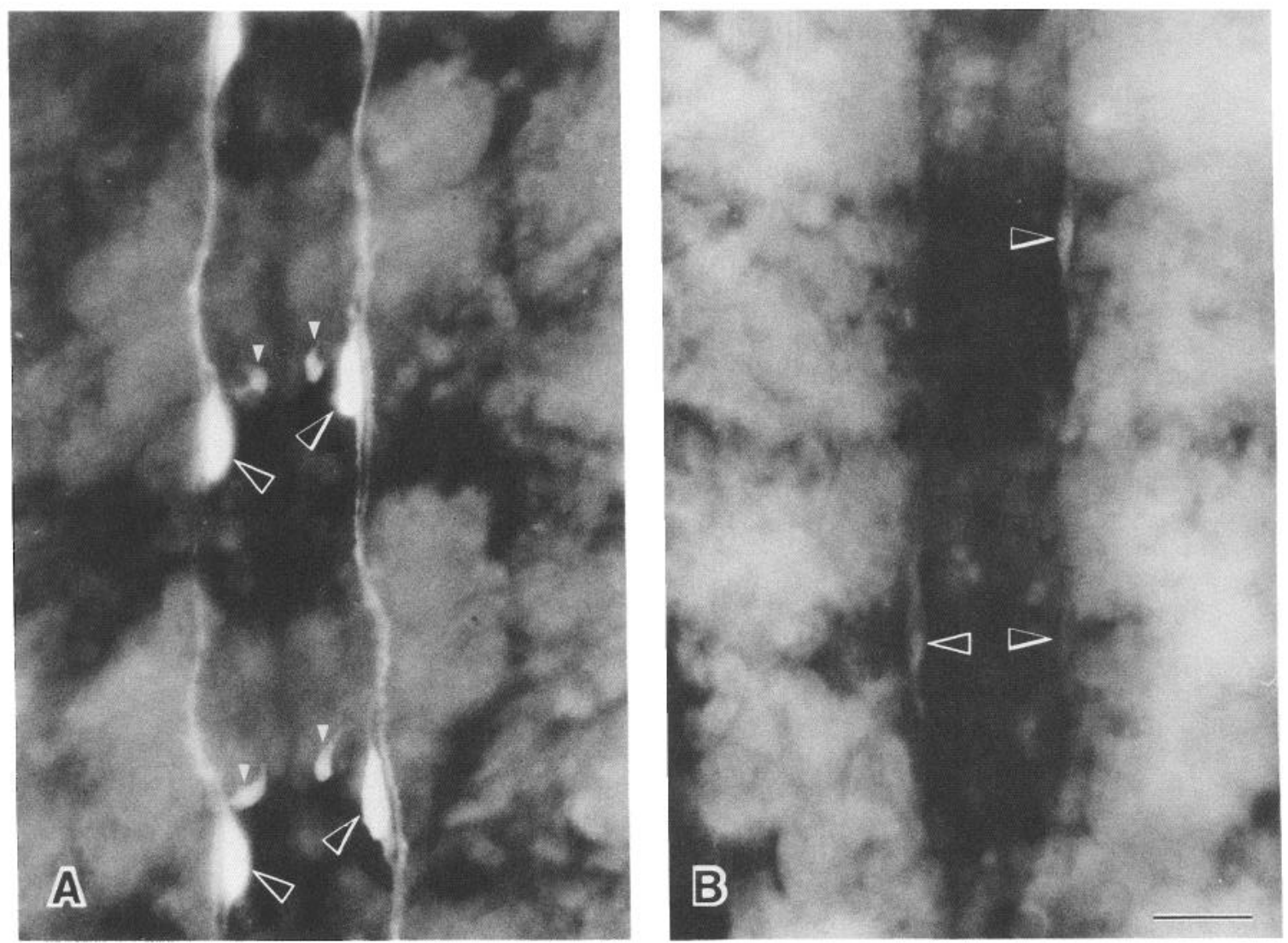

Figure 2. Labeling of bipolar cells with Laz1-1 at $7.5 \mathrm{~d}$ of age. A, Bipolar cells in SG2 and SG3 are indicated by black arrowheads. In SG2, processes of bipolar cells from adjacent ganglia can be seen within the neuropil. The more medial pair of cells also labeled by Laz1-1 are indicated by the small, white arrowheads. The left and right halves of SG2 and SG3 have not completely fused together. B, Bipolar cells in SG14 and SG15 are indicated by black arrowheads. Anterior is towards the top. Bar in $B, 20 \mu \mathrm{m}$ for both panels.

\section{Degeneration of bipolar cells}

When we examined 9-d-old embryos labeled with Laz1-1, we found bipolar cells in several anterior segmental ganglia (SG1SG9) in the process of degeneration (we did not examine the head ganglion). From the study of several specimens 9-12 d old labeled with Laz1-1, we were able to determine that degeneration of these cells occurs in the following sequence. Initially, there is a loss of labeling of the anterior and posterior processes, which appear to atrophy or retract (as confirmed by dye injection; discussed below). This is followed by a progressive decrease in the intensity of labeling with Laz1-1 (compared to other bipolar cells judged to be healthy in the same specimen) and the fragmentation of the cell into pieces that are identifiable since they remain immunoreactive to Lazl-1 (Fig. 5). In some cases, the dying cell or its fragments appear to have moved posteriorly, outside the ganglion, before entirely disappearing. We presume that the fragments are phagocytosed, but we have not examined this process with the electron microscope.

The retraction or atrophy of processes was confirmed by injecting Lucifer yellow into bipolar cells that were clearly in the process of degenerating in several 10-d-old embryos (Fig. 4B). In 3 cases, the cells still had short longitudinal processes devoid of any secondary branching, and in the other 3 they lacked processes entirely.

The degeneration of bipolar cells occurs first in anterior segments and sequentially in more posterior ones, with all the cells eventually disappearing. From the examination of 12 embryos
9-12 d of age, it appears that degeneration of these cells begins at about $9 \mathrm{~d}$ in anterior segmental ganglia (before bipolar cells are evident in the most posterior neuromeres) and is complete by about $13 \mathrm{~d}$.

The spatiotemporal patterns of labeling with Laz1-1 and of degeneration of the bipolar cells in embryos 7-13 d old are summarized in Table 1. From these data we infer that bipolar cells are generated rostrocaudally, appearing in about 1 segment every $3 \mathrm{hr}$. They degenerate in the same sequence and at about the same rate, though the time when they degenerate in a particular segment varies somewhat; no 2 embryos of the same nominal age showed exactly the same pattern of bipolar cell death. Our data also indicate that the bipolar cells in ganglia posterior to SG11 survive for about 2.5-3 d after they first label with Laz1-1 (see Table 1).

\section{Discussion}

Our observations have shown that a bilateral pair of bipolar cells appears early in the development of each of the 32 metameric neuromeres of the leech embryo, in a sequence that starts anteriorly, culminates posteriorly, and takes about $3 \mathrm{~d}$. As they differentiate, these cells extend processes ipsilaterally both rostrally and caudally and express antigens recognized by the MAb Laz1-1. The processes extend to several adjacent segments. The cells survive for a period of 2-3 d and then degenerate throughout the ventral nerve cord. Two questions prompted by our observations merit further discussion. 

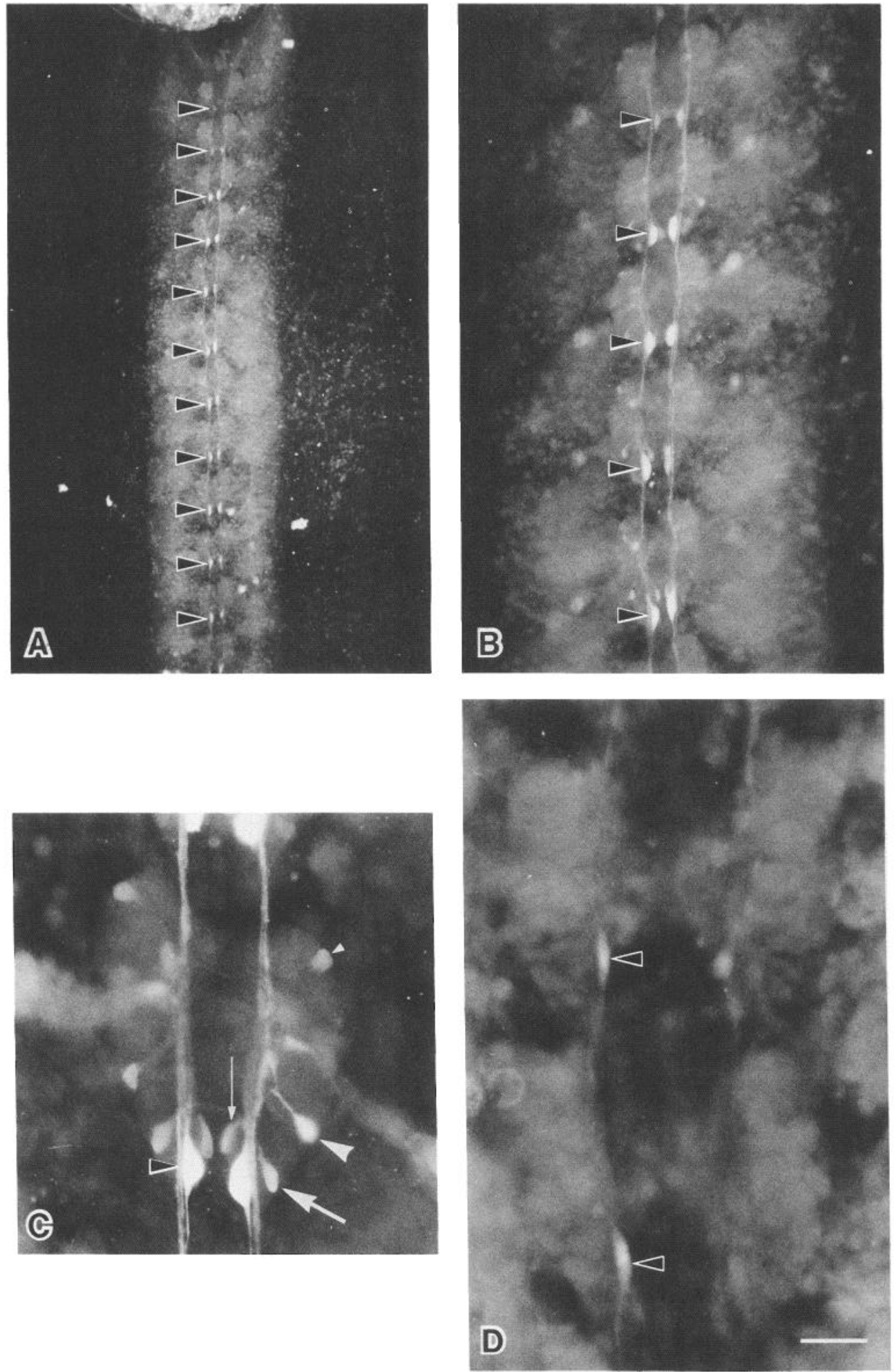

Figure 3. Labeling of bipolar cells with Laz1-1 at $8 \mathrm{~d}$. A, Germinal plate at low magnification. Pairs of bipolar cells are indicated by black arrowheads. The first 11 segments containing $\mathrm{H} 1-\mathrm{H} 4$ and SG1-SG7 are included in the photograph. A portion of the larval mouth is present anteriorly. $B$, Germinal plate at higher magnification than in $A$. Bipolar cells in H2-SG2 are indicated by black arrowheads. $C$, High-magnification micrograph of segmental ganglion 1 . This $8 \mathrm{~d}$ embryo is not the same as the one shown in $A, B$, and $D$. The ganglion has fused completely and is heart-shaped. The small, white arrowhead indicates an unidentified cell on the dorsal side of the ganglion which does not label in more mature embryonic ganglia. The large, white arrowhead points to the right lateral No. 1 (L1) cell described in Steward (1985). The large, white arrow indicates the first 4-7 bilateral pairs of cells that label in the posterior dorsolateral region of $20 \mathrm{~d}$ embryonic ganglia. The small, white arrowhead indicates the right cell of the pair medial to the bipolar cells. Processes within the neuropil of the ganglion are principally from CNS neurons, since the first growth cones of peripheral neurons also labeled by Laz1-1 have just begun to enter the ganglion via the anterior roots at this stage. $D$, Left bipolar cells are labeled in SG15 and SG16, as indicated by black arrowheads. Anterior is towards the top. Bar in $D: 130 \mu \mathrm{m}$ in $A, 50 \mu \mathrm{m}$ in $B$, and $20 \mu \mathrm{m}$ in $C$ and $D$.

\section{What type of cells are bipolar cells?}

Are the bipolar cells muscle, glial, or nerve cells? Several observations favor the last possibility. The fact that all other cells that express antigens recognized by Laz1-1 are apparently neurons (Stewart, 1985; R. R. Stewart, B. Zipser, and E. R. Macagno, unpublished observations) supports such an identification for the bipolar cells. Laz1-1 is 1 of 3 monoclonal antibodies (the others are Laz2-1 and Lan3-6) that stain the same subset of ganglionic neurons in the leech Haemopis marmorata (Zipser and McKay, 1981; Zipser, 1982; Macagno et al., 1983; Zipser et al., 1983; Stewart, 1985; Stewart et al., 1985). These 3 antibodies were generated in separate fusions with mice that were immunized with homogenates of whole nerve cords from adults of this species. All 3 antibodies label peripheral sensory afferents as well as primary sensory neurons, modulatory neurons, and 
a distinct set of unidentified neurons in the CNS. They appear to be neuron-specific and do not react with non-neuronal tissues. Laz1-1 and Laz2-1, but not Lan3-6, cross-react with neurons of Hirudo medicinalis (Stewart, 1985, and unpublished observations), the species used for the present studies. It is interesting to note, however, that we found no evidence that any other Laz1-1-positive cell degenerates during gangliogenesis. The morphology of the bipolar cells is also more typical of that seen in leech neurons (particularly processes extending distances that span several segments) than of the morphology of the large glial cells. Bipolar cells also arborize, though not extensively, in the neuropils of the ganglia they project to or through, which is more characteristic of neurons than of glial cells.

Another feature of bipolar cells that argues, albeit weakly, against their being glial cells is the absence of dye-coupling. Intracellular injections failed to show any passage of Lucifer yellow from one bipolar cell to another, or to any other cell. Initial dye-coupling to neighboring undifferentiated neurons, followed by uncoupling as they differentiate, has been reported for developing neurons in the leech (Kramer and Kuwada, 1983) and in the grasshopper (Goodman and Spitzer, 1979). Glial cells, on the other hand, tend to remain dye-coupled. For example, in early and late embryos of Haementeria (Kramer and Weisblat, 1985) and Hirudo (unpublished observations), glial cells of the ganglia and connectives remain dye-coupled to one another.

Lastly, it is unlikely that bipolar cells are muscle cells, since they are not labeled by the MAb Lan3-14. In adult Haemopis, Lan3-14 labels the muscles of the connectives (Zipser and McKay, 1981; Hockfield and McKay, 1983), and in embryos of the glossiphoniid leech Haementeria it labels muscle cells and particular glial cells (Stuart et al., 1982; Kuwada, 1985). In Hirudo embryos, only cryptolarval muscle cells that surround the yolk and muscle cells of the definitive embryo are labeled by Lan314 (A. Peinado and R. R. Stewart, unpublished observations).

The evidence is clearly not conclusive but, on balance, it favors the identification of the bipolar cells as nerve cells.

\section{Why do all the bipolar cells die?}

Bipolar cells die from days 9-12 of embryogenesis, a period of development in which the number of cells within segmental ganglia is declining (Stewart et al., 1986; C. Baptista, W.-Q. Gao, and E. Macagno, unpublished observations). The reasons for the death of these cells are not known, but their death may be a reflection of their having a temporary function during development: Cells that perform a specific task and then die have been reported in the development of the nervous systems of several invertebrates (reviewed in Truman and Schwartz, 1982; Truman, 1984).

\footnotetext{
Figure 4. Double-labeling of bipolar cells with Lucifer yellow and Laz1-1. $A 1, A 2$, Photomicrographs of SG4-SG6 in a 9 d embryo, showing 2 bipolar cells (arrows) filled with Lucifer yellow in $A I$ and labeling of the bipolar cells (arrows) with Laz1-1 in A2. The bipolar cell on the right in SG4 extends its anterior process as far as the head ganglion and its posterior process to SG6. The bipolar cell on the left side of SG5 extends anteriorly into SG1 and posteriorly beyond SG6, but not as far as SG7. Note the fine secondary branches of the cells in the neuropils of SG4 and SG5. The round white spots in $A 2$ are fluorescent debris from treatment with the rhodamine-coupled second antibody. $B 1, B 2$, Photomicrographs of SG17 and SG18 in a $10 \mathrm{~d}$ embryo, showing a
}
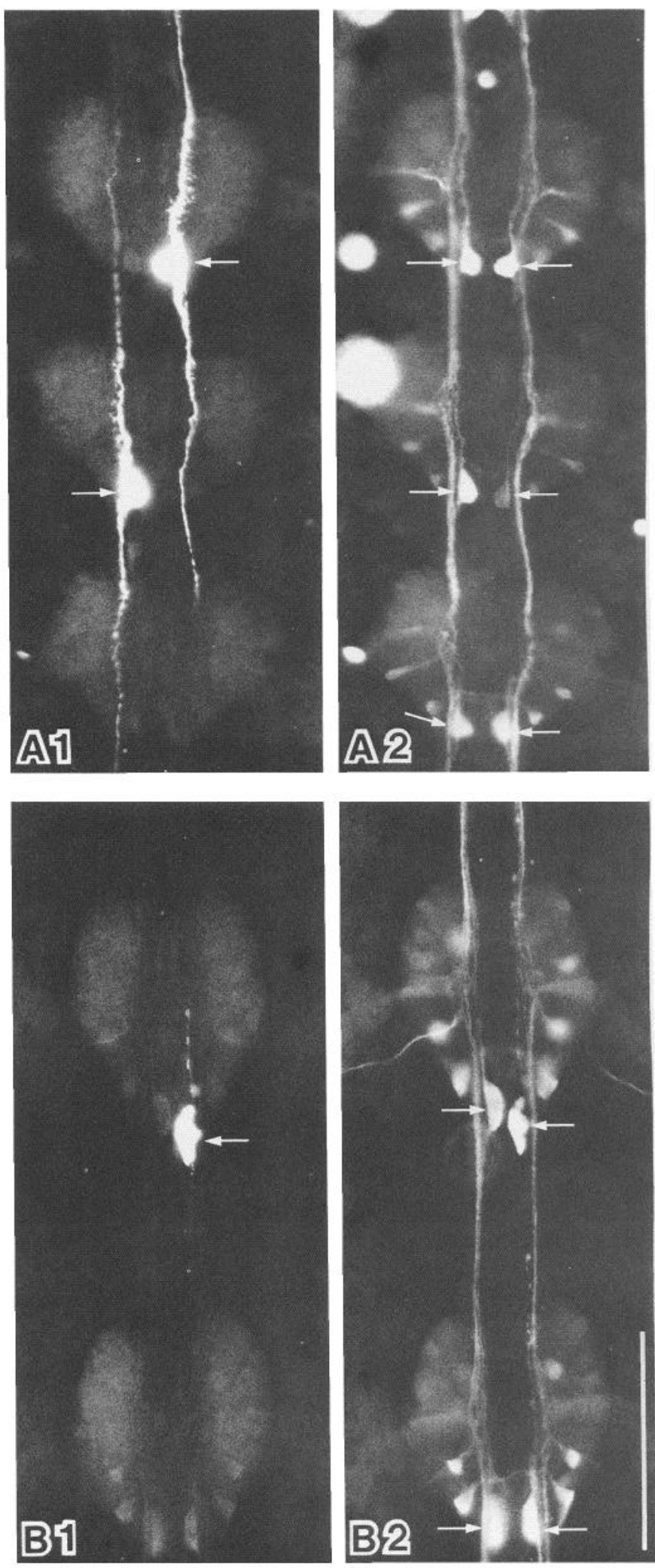

dying bipolar cell (arrow) filled with Lucifer yellow in BI and labeling of the bipolar cells (arrows) with Laz1-1 in B2. Some breakthrough of the rhodamine fluorescence from the second antibody can be seen in $B 1$. Note that the filled cell is almost completely devoid of processes, with only a short, thin process with varicosities, which is characteristic of an atrophying process, extending into the neuropil of SG17. Bar in $B 2,100 \mu \mathrm{m}$ for all panels. 

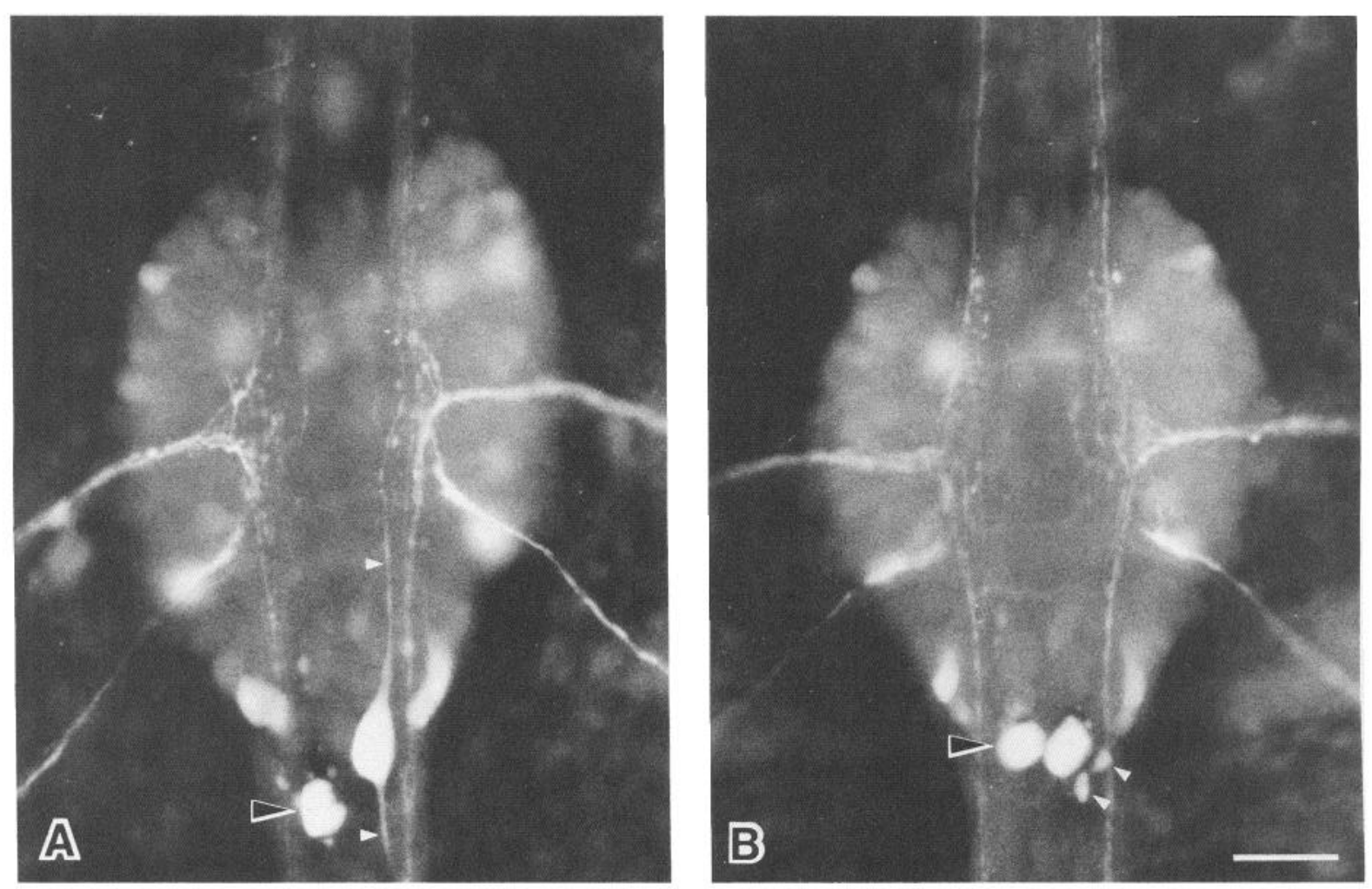

Figure 5. Labeling of bipolar cells with Laz1-1 at $9.5 \mathrm{~d}$. A, Bipolar cell in SG3. Small, white arrowheads indicate the anterior and posterior processes of the right bipolar cell. The black arrowhead indicates the left bipolar cell, which is degenerating. Small, immunoreactive fragments are seen surrounding the degenerating cell. $B$, Bipolar cells in SG5 of the same embryo. Both bipolar cells are degenerating in this instance. The anterior and posterior processes of both bipolar cells are not labeled, and are consequently judged to be dying. Black arrowhead indicates the left bipolar cell. Small, white arrowheads point to immunoreactive fragments of the degenerating right bipolar cell. In both ganglia, axons from peripheral and CNS neurons are seen within the neuropil. Scale bar in $B, 20 \mu \mathrm{m}$ for both $A$ and $B$.

One possible function for the bipolar cells follows from the observation that they extend processes at an early stage of gangliogenesis, when adjacent ganglionic primordia on each side of the midplane of the animal are closely apposed and the bilateral longitudinal tracts have yet to form, or are in the process of being established. With time, and before the bipolar cells degenerate, these tracts enlarge as many other cells extend projections along these longitudinal pathways, all along the length of the nerve cord. These observations suggest a role for the bipolar cells in the establishment of these longitudinal tracts, or possibly in organizing select bundles of axons within them by providing an appropriate substrate for axons that grow at later times. Such roles for the earliest neurons in extending axons (then called "lead fibers") were indicated by the early work of LoPresti et al. (1973) on Daphnia visual system development. More recently, Bate, Goodman, and their colleagues have identified cells that participate in the establishment of longitudinal tracts in the grasshopper CNS (Bate and Grunewald, 1981; Raper et al., 1983a, b; Bastiani et al., 1985). Although we lack the evidence to demonstrate that bipolar cells are similarly involved in leech CNS development, it is of interest to note that many of the progeny of the midline precursor (MP) cells in the grasshopper CNS, which presumably lay down the earliest pathways, also die (Bate et al., 1981; Goodman et al., 1981; Loer et al., 1983). An important difference between the MP progeny and the bipolar cells is that whereas the latter die in all segments, the former all die only in the abdominal segments. In the thorax, some die in the third thoracic segment and none in the anterior
2. The surviving MP progeny, however, lose their initial projections, extend new ones, and take on new functions (Goodman et al., 1981).

If the bipolar cells are the earliest cells to extend processes between ganglionic primordia, what substrate do they follow? Kuwada and Kramer (1983) have suggested, from their studies of the development of central neurons in the glossiphoniid leech Haementeria ghilianii, that growth cones of ganglionic neurons might follow the processes of the 2 pairs of connective muscle cells found in each segment. In that species, these cells have longitudinal extensions before neurons of the ganglionic primordia have begun to differentiate. We do not know whether these cells are also available early enough to serve as a bipolar cell pathway in Hirudo. If not, another possible substrate for the bipolar cells could be the extracellular matrix, as has been shown to be the case in the grasshopper (Goodman et al., 1982) for other types of cells.

Although the termination of a function seems a reasonable explanation for the death of the bipolar cells, it is by no means the only plausible one. For example, these cells could be generated through obligatory patterns of cell division in spite of the fact that they have no particular function. They would grow for a while and search for targets along the ventral nerve cord and, failing to find them, die. Possibly in other or in ancestral species such a target existed. Another explanation could be that a different type of cell competes successfully with the bipolar cells, depriving them of a critical factor. Clearly, several hypotheses can be proposed, and the best resolution of the problem of 
Table 1. Bipolar cells in embryos 7-13 d old

\begin{tabular}{|c|c|c|c|c|c|c|c|c|c|c|c|}
\hline \multirow[b]{2}{*}{$\begin{array}{l}\text { Segmental } \\
\text { ganglion }^{a}\end{array}$} & \multicolumn{11}{|c|}{ Embryonic age (d) ${ }^{b}$} \\
\hline & $\frac{7.0}{1 \mathrm{r}}$ & $\frac{7.5}{1 \mathrm{r}}$ & $\frac{8.0}{1 \mathrm{r}}$ & $\frac{8.5}{1 \mathrm{r}}$ & $\frac{9.0}{1 \mathrm{r}}$ & $\frac{9.5}{1 \mathrm{r}}$ & $\frac{10.0}{1 \mathrm{r}}$ & $\frac{10.5}{1 \mathrm{r}}$ & $\frac{11.0}{1 \mathrm{r}}$ & $\frac{12.0}{1 \mathrm{r}}$ & $\frac{13.0}{1 . r}$ \\
\hline SG1 & $\infty$ & $\infty$ & $\infty$ & $\infty$ & $x x$ & $x x$ & $x x$ & & & & \\
\hline SG2 & $\infty$ & $\infty$ & $\infty$ & $\infty$ & $\infty$ & $x x$ & $x x$ & & & & \\
\hline SG3 & $\infty$ & $\infty$ & $\infty$ & $\infty$ & $x x$ & $\infty$ & $x x$ & $x x$ & & & \\
\hline SG4 & $\infty$ & $\infty$ & $\infty$ & $\infty$ & OX & $x x$ & $x x$ & & $x x$ & & \\
\hline SG5 & $\infty$ & $\infty$ & $\infty$ & $\infty$ & $x x$ & & & $x \times$ & $x \times$ & & \\
\hline SG6 & $\infty$ & $\infty$ & $\infty$ & $\infty$ & $\times 0$ & $x \times$ & $x x$ & & & & \\
\hline SG7 & $\infty$ & $\infty$ & $\infty$ & $\infty$ & $\infty$ & $x \times$ & $x \times$ & $x x$ & $x x$ & & \\
\hline SG8 & $\infty$ & $\infty$ & $\infty$ & $\infty$ & $\infty$ & $x x$ & $x x$ & & $x x$ & & \\
\hline SG9 & $\infty$ & $\infty$ & $\infty$ & $\infty$ & $\infty$ & $x x$ & $x x$ & $x x$ & & & \\
\hline SG10 & $\infty$ & $\infty$ & $\infty$ & $\infty$ & $\infty$ & $x x$ & $\infty$ & & $x \times$ & & \\
\hline SG11 & $\infty$ & $\infty$ & $\infty$ & $\infty$ & $\infty$ & $\infty$ & $x x$ & $x x$ & & & \\
\hline SG12 & & $\infty$ & $\infty$ & $\infty$ & $\infty$ & $\infty$ & $\infty$ & $x x$ & & & \\
\hline SG13 & & $\infty$ & $\infty$ & $\infty$ & $\infty$ & $\infty$ & $x x$ & $x \times$ & $x x$ & & \\
\hline SG14 & & $\infty$ & $\infty$ & $\infty$ & $\infty$ & $\infty$ & $x x$ & $x x$ & $x x$ & & \\
\hline SG15 & & $\infty$ & $\infty$ & $\infty$ & $\infty$ & $O X$ & $x x$ & $x x$ & $x x$ & & \\
\hline SG16 & & & $\infty$ & $\infty$ & $\infty$ & $\infty$ & $\times 0$ & $x x$ & $x x$ & & \\
\hline SG17 & & & $\infty$ & $\infty$ & $\infty$ & $\infty$ & ox & ox & & & \\
\hline SG18 & & & $\infty$ & $\infty$ & $\infty$ & $\infty$ & $\infty$ & $O x$ & $x x$ & & \\
\hline SG19 & & & $\infty$ & $\infty$ & $\infty$ & $\infty$ & $\infty$ & $\times 0$ & & $x x$ & \\
\hline SG20 & & & & $\infty$ & $\infty$ & $\infty$ & $\infty$ & $\infty$ & & $x \times$ & \\
\hline SG21 & & & & $\infty$ & $\infty$ & $\infty$ & $\times 0$ & ox & $x x$ & & \\
\hline $\mathrm{T} 1$ & & & & $\infty$ & $\infty$ & $\infty$ & $\infty$ & $\infty$ & & $x x$ & \\
\hline $\mathrm{T} 2$ & & & & $\infty$ & $\infty$ & $\infty$ & $\infty$ & $\infty$ & & & \\
\hline T3 & & & & & $\infty$ & $\infty$ & $\infty$ & $\infty$ & $x x$ & & \\
\hline T4 & & & & & $\infty$ & $\infty$ & $\infty$ & $\infty$ & & & \\
\hline T5 & & & & & xo & $\infty$ & $\infty$ & $\infty$ & $x x$ & & \\
\hline T6 & & & & & $\infty$ & $\infty$ & $\infty$ & $\infty$ & $\infty$ & & \\
\hline $\mathrm{T} 7$ & & & & & & $\infty$ & $\infty$ & $\infty$ & $\infty$ & ox & \\
\hline
\end{tabular}

$1, r$, Left and Right sides of the ganglia. $O$, Healthy bipolar cell stained with Lazl-1. $\times$, Dying bipolar cell stained with Lazl-1. Blank space, bipolar cell missing.

${ }^{a}$ SG1-SG21, segmental ganglia of the body; T1-T7, metameres of the tail ganglion.

${ }^{b}$ The data for 7.0,7.5 and $8.0 \mathrm{~d}$ embryos are averages of 3 specimens at each age, the data for $8.5 \mathrm{~d}$ are the average for

2 specimens, while the rest represent single specimens. Some variation in the pattern is seen at each age.

selecting the correct one would be to determine the function of the bipolar cells.

In summary, we have described a type of cell that appears throughout the leech ventral nerve cord and then disappears entirely. We believe that these cells are neuronal in nature, and propose that their function concerns the establishment of longitudinal pathways. We know of no other case among invertebrates in which a type of cell appears, differentiates, and then completely disappears during development of the CNS. A precedent exists in the development of the spinal cord of lower vertebrates, however: The Rohon-Beard cells do this exactly (Spitzer and Lamborghini, 1981).

\section{References}

Anderson, H. (1978) Postembryonic development of the visual system of the locust Schistocerca gregaria. I. Patterns of growth and developmental interactions in the retina and optic lobe. J. Embryol. Exp. Morphol. 45: 55-83.

Bastiani, M. J., C. Q. Doe, S. L. Helfand, and C. S. Goodman (1985) Neuronal specificity and growth cone guidance in grasshopper and Drosophila embryos. Trends Neurosci. 8: 257-266.

Bate, C. M., and E. B. Grunewald (1981) Embryogenesis of an insect nervous system. II. A second class of neuron precursor cells and the origin of the intersegmental connectives. J. Embryol. Exp. Morphol. 61: 317-330.

Bate, C. M., C. S. Goodman, and N. C. Spitzer (1981) Embryonic development of identified neurons: Segment-specific differences in the $\mathrm{H}$ cell homologues. J. Neurosci. 1: 103-106.

Fernandez, J., and G. S. Stent (1982) Embryonic development of the hirudinid leech Hirudo medicinalis: Structure, development and segmentation of the germinal plate. J. Embryol. Exp. Morphol. 72: 7196.

Goodman, C. S., and N. C. Spitzer (1979) Embryonic development of identified neurons; differentiation from neuroblast to neurone. Nature 280: 208-214.

Goodman, C. S., M. Bate, and N. C. Spitzer (1981) Embryonic development of identified neurons: Origin and transformation of the $\mathrm{H}$ cell. J. Neurosci. 1: 94-102.

Goodman, C. S., J. A. Raper, R. Ho, and S. Chang (1982) Pathfinding by neuronal growth cones in grasshopper embryos. Symp. Soc. Dev. Biol. 40: 275-316.

Hamburger, V., and R. W. Oppenheim (1982) Naturally occurring neuronal death in vertebrates. Neurosci. Comment. 1: 39-55.

Hockfield, S., and R. McKay (1983) Monoclonal antibodies demonstrate the organization of axons in the leech. J. Neurosci. 3: 369-375.

Horvitz, H. R., H. M. Ellis, and P. W. Sternberg (1982) Programmed cell death in nematode development. Neurosci. Comment. 1: 56-65. 
Kramer, A. P., and J. Y. Kuwada (1983) Formation of the receptive fields of leech mechanosensory neurons during embryonic development. J. Neurosci. 3: 2474-2486.

Kramer, A. P., and D. A. Weisblat (1985) Developmental neural kinship groups in the leech. J. Neurosci. 5: 388-407.

Kuwada, J. Y. (1985) Pioneering and pathfinding by an identified neuron in the embryonic leech. J. Embryol. Exp. Morphol. 86: 155167.

Kuwada, J. Y., and A. P. Kramer (1983) Embryonic development of the leech nervous system: Primary axon outgrowth of identified neurons. J. Neurosci. 3: 2098-2111.

Lamborghini, J. E. (1981) Kinetics of Rohon-Beard neuron disappearance in Xenopus laevis. Soc. Neurosci. Abstr. 7: 291.

Loer, C. M., J. D. Steeves, and C. S. Goodman (1983) Neuronal cell death in grasshopper embryos: Variable patterns in different species, clutches and clones. J. Embryol. Exp. Morphol. 78: 169-182.

LoPresti, V., E. R. Macagno, and C. Levinthal (1973) Structure and development of neuronal connections in isogenic organisms: Cellular interactions in the development of the optic lamina of Daphnia magna. Proc. Natl. Acad. Sci. USA 70:56-61.

Macagno, E. R. (1979) Cellular interactions and pattern formation in the development of the visual system of Daphnia magna (Crustacea, Branchiopoda). I. Interactions between embryonic retinular fibers and laminar neurons. Dev. Biol. 73: 206-238.

Macagno, E. R. (1980) Number and distribution of neurons in leech segmental ganglia. J. Comp. Neurol. 190: 283-302.

Macagno, E. R., R. R. Stewart, and B. Zipser (1983) The expression of antigens by embryonic neurons and glia in segmental ganglia of the leech Haemopis marmorata. J. Neurosci. 3: 1746-1759.

Muller, K., J. Nicholls, and G. Stent (1981) Neurobiology of the Leech, pp. 256-257, Cold Spring Harbor Laboratory, Cold Spring Harbor, New York.

Nordlander, R. H., and J. S. Edwards (1968) Morphological cell death in the postembryonic development of the insect optic lobes. Nature 218: 780-781.

Nordlander, R. H., and J. S. Edwards (1969) Postembryonic brain development in the monarch butterfly Danaus plexippus plexippus, L. I. Cellular events during brain morphogenesis. Arch. Dev. Biol. (Roux) 162: 197-217.

Purves, D., and J. W. Lichtman (1985) Principles of Neural Development, pp. 131-153, Sinauer, Sunderland, MA.

Raper, J. A., M. Bastiani, and C. S. Goodman (1983a) Pathfinding by neuronal growth cones in grasshopper embryos I. Divergent choices made by the growth cones of sibling neurons. J. Neurosci. 3: 20-30.

Raper, J. A., M. Bastiani, and C. S. Goodman (1983b) Pathfinding by neuronal growth cones in grasshopper embryos II. Selective fasciculation onto specific axonal pathways. J. Neurosci. 3: 31-41.

Spitzer, N. C., and J. E. Lamborghini (1981) Programs of early neuronal development. In Studies in Developmental Neurobiology, W. M. Cowan, ed., pp. 261-287, Oxford U. P., New York.

Stent, G. S., and D. A. Weisblat (1985) Cell lineage in the development of invertebrate nervous systems. Annu. Rev. Neurosci. 8: 45-70.

Stewart, R. R. (1985) The genesis of segmental differences in two species of leeches. Ph.D. dissertation, Columbia University, NY.

Stewart, R R., and E. R. Macagno (1985) Differentiation and death of cells in the leech CNS. I. The bipolar cells. Soc. Neurosci. Abstr. 11: 957 .

Stewart, R. R., E. R. Macagno, and B. Zipser (1985) The embryonic development of peripheral neurons in the body wall of the leech Haemopis marmorata. Brain Res. 332: 150-157.

Stewart, R. R., D. Spergel, and E. R. Macagno (1986) Segmental differentiation in the leech nervous system: The genesis of cell number in the segmental ganglia of Haemopis marmorata. J. Comp. Neurol. 253: 253-259.

Stuart, D. K., I. Thompson, D. A. Weisblat, and A. P. Kramer (1982) Antibody staining of embryonic leech muscle, blast cell migration, and neuronal pathway formation. Soc. Neurosci. Abstr. 8: 15.

Sulston, J. E., and H. R. Horvitz (1977) Postembryonic cell lineages in the nematode Caenorhabditis elegans. Dev. Biol. 56: 110-156.

Truman, J. W. (1984) Cell death in invertebrate nervous systems. Annu. Rev. Neurosci. 7: 171-188.

Truman, J. W., and L. M. Schwartz (1982) Insect systems for the study of programmed neuronal death. Neurosci. Comment. 1: 66-72.

Zackson, S. L. (1984) Cell lineage, cell-cell interaction, and segment formation in the ectoderm of a glossiphoniid leech embryo. Dev. Biol. 104: $143-160$.

Zipser, B. (1982) Complete distribution patterns of neurons with characteristic antigens in the leech central nervous system. J. Neurosci. 2: 1453-1464.

Zipser, B., and R. McKay (1981) Monoclonal antibodies distinguish identifiable neurones in the leech. Nature 289: 549-554.

Zipser, B., R. R. Stewart, T. Flanagan, M. Flaster, and E. R. Macagno (1983) Do monoclonal antibodies stain sets of functionally related leech neurons? Cold Spring Harbor Symp. Quant. Biol. 68: 551-556. 